\title{
SISTEM OTOMASI SEBAGAI UPAYA PERBAIKAN KUALITAS DENGAN METODE SPC PADA LINE FINISHING (STUDI KASUS: PT. X)
}

\author{
Alex Bagus Dewantara dan Muhammad Kholil \\ Program Studi Teknik Industri Universitas Mercu Buana Jakarta \\ e-mail: alexbagusdw@gmail.com; m.kholil2009@gmail.com
}

\begin{abstract}
ABSTRAK
PT. X merupakan perusahaan manufaktur komersial yang mengolah bijih plastik. Produk yang dihasilkan oleh perusahaan ini adalah kemasan tube, botol, peralatan otomotif dan kemasan plastik. Kemasan tube merupakan produk yang permintaannya paling tinggi. PT. X memiliki banyak kompetitor dan tetap menjaga kualitas produk agar bisa bersaing dengan perusahaan kompetitor. Penelitian ini menggunakan analisis Statistical Process Control (SPC) yaitu analisis pengambilan keputusan secara analitis yang memperlihatkan suatu proses berjalan dengan baik atau tidak. Tujuan penelitian ini untuk menganalisis tingkat efektifitas pengendalian kualitas menggunakan alat bantu statistik. Alat bantu yang digunakan berupa check sheet dan histogram digunakan untuk mengumpulkan data sedangkan untuk analisis penyebab masalah menggunakan peta kendali p, diagram pareto dan diagram sebab akibat. Berdasarkan diagram pareto dapat diketahui jumlah cacat dan jenis cacat. Lima besar penyumbang cacat dari total output yaitu kotor dalam 56\%, scratch 32\%, warna cap 4\%, cap pecah 3\% dan header cacat 3\%. Dari analisis diagram sebab akibat dapat diketahui faktor penyebab kerusakan berasal dari aspek manusia, mesin, metode kerja, material dan lingkungan kerja. Dari hasil analisis tersebut perusahaan dapat mengambil tindakan perbaikan untuk menekan tingkat cacat dan meningkatkan produktifitas dengan mesin sistem otomasi. Dari hasil implementasi diperoleh penurunan rata-rata dari $7,65 \%$ menjadi $1,14 \%$.
\end{abstract}

Kata Kunci: Statistical Process Control, Kualitas, Perbaikan, Otomasi.

\begin{abstract}
PT. $X$ is a commercial plastic packaging manufacture. This company produced such as tube packaging bottles, automotive equipment and plastic packaging. Tube packaging is a product that high in demand. PT. $X$ has many competitors and maintains the quality of products in order to compete with competitors. This study uses analysis Statistical Process Control (SPC) which is a decision-making analysis that showing a process running well or not. The purpose of this study was to analyze the effectiveness of quality control using statistical tools after improvement with automastic sistem machine. Statistical Tools using check sheet and histogram which used to collect the data while analyzing the cause of the problem using p control chart, Pareto diagram and a causal diagram. Based on Pareto diagram it can be seen the number of defects and type of defect. Five major contributor non conformity product of the total output is foreign matter 56\%, scratch 32\%, cap substandard colour 4\%, broken cap 3\% and header deformed 3\%. From the analysis of causal c chartan be seen the problem factors from the human aspect, machinery, working methods, materials and working environment. From this analysis the company can take action improvement to reduce the level of non conformity product and increase productivity with machine automation system. From the results obtained by the implementation of a decrease in average product that is rejected from $7.65 \%$ to $1.14 \%$.
\end{abstract}

Keyword: Statistical Process Control, Quality, Improvement, Automation

\section{PENDAHULUAN}

Sebagai sebuah perusahaan manufaktur komersial, PT. X merupakan perusahaan manufaktur yang mengolah bijih plastik. Produk yang dihasilkan oleh perusahaan ini adalah kemasan tube, botol, peralatan otomotif dan kemasan plastik. Kemasan tube merupakan produk yang tinggi permintaan untuk di perusahaan ini. Perusahaan ini memiliki banyak kompertitor untuk produk kemasan tube, tentunya untuk menghadapi permasalahan tersebut perusahaan mempersiapkan strategi untuk memperoleh profit secara maksimal dari produk-produk yang dihasilkan dan tetap menjaga kualitas produk agar bisa bersaing dengan perusahaan kompetitor. Faktor-faktor yang mempengaruhi biaya produksi secara garis besar, dari sudut pandang sisi produksi, adalah biaya material, energi, dan tenaga kerja. Jika proses produksi dipercepat atau dengan kata 
lain cycle time di persingkat maka downtime dapat ditekan sehingga produktifitas bisa meningkat dengan output yang banyak, selain itu improvement ini menggunakan sistem otomasi jadi bisa mengurangi man power atau karyawan dan profit perusahaan akan meningkat. Identifikasi masalah yang dibahas dalam penelitian ini adalah sebagai berikut: faktor yang menyebabkan cacat dominan pada line finishing process, perbaikan yang dapat dilakukan untuk mengatasi masalah kualitas cacat dominan, perbaikan dengan sistem otomasi pada produksi terutama di line finishing process. Tujuan penelitian yang dibahas dalam penelitian ini adalah merekomendasikan perbaikan pada faktor-faktor penyebab cacat dominan produk, menganalisis dampak perbaikan yang dilakukan untuk meningkatkan kualitas, meminimalkan cacat produk pada line finishing process dengan sistem otomasi.

\section{TINJAUAN PUSTAKA}

\section{Kualitas}

Definisi kualitas dipengaruhi oleh cara pandang yang bersifat subyektif dari setiap orang. Kualitas sendiri sering dianggap sebagai ukuran relatif kebaikan setiap produk atau jasa yang terdiri atas kualitas desain atau rangcangan dan kualitas kesesuaian atau kecocokan. Kata "quality" itu sendiri diartikan sebagai pemikiran yang dinamis oleh Edward Sallis. Nilai moral dan emosional yang terkandung dalam kata kualitas menjadikannya sulit didefenisikan secara akurat. Ada lima pendekatan yang dapat digunakan untuk mendefinisikan kualitas [1].

Pendekatan Transenden adalah kualitas didefinisikan sebagai pencapaian atau untuk standard tertinggi pemuasan kebutuhan terhadap konsumen. Pendekatan berdasarkan Produk. Pendekatan ini adalah pendekatan kuantitatif yang menggunakan karakteristikkarakteristik yang dapat dihitung dan terukur. Kualitas didefenisikan menjadi suatu angka, dimana semakin mendekati ukuran yang telah disepakati maka kualitasnya terbaik [2].

Pendekatan berdasarkan konsumen adalah kualitas didefinisikan menjadi fitness for use. Kualitas dinilai baik apabila berhasil memenuhi kebutuhan pemakainya [3]. Pendekatan manufaktur, pendekatan ini berhubungan dengan pemenuhan design atau spesifikasi. Kualitas dianggap bebas dari kesalahan (error). Dalam hal ini, kesalahan adalah ketidaksesuaian terhadap peraturan design atau spesifikasi [4].

\section{Otomasi}

Otomasi adalah suatu teknologi terkait dengan aplikasi mekanik, elektronik, dan komputer didasarkan sistem untuk beroperasi dan mengendalikan produksi. Teknologi ini meliputi [5]:

a. Alat mesin otomatis untuk memproses part

b. Mesin perakitan otomatis

c. Robot industri

d. Material otomatis yang menangani dan sistem gudang atau penyimpanan

e. Sistem pemeriksaan otomatis untuk pengendalian mutu

f. Pengawasan proses komputer kontrol balik

g. Sistem komputer untuk perencanaan, pengumpulan data, dan pengambilan keputusan untuk mendukung memproduksi.

Jenis Otomasi untuk sistem produksi dapat digolongkan ke dalam tiga jenis basis dasar [5]:

a. Otomasi yang ditetapkan perbaiki atau fixed automation

b. Otomasi programmable

c. Otomasi fleksibel

\section{Pengendalian Kualitas Proses Statistik (SPC)}

Pengendalian kualitas statistik (statistical quality control) secara garis besar digolongkan menjadi dua, yakni pengendalian proses statistik (statistical process control) dan rencana penerimaan sample produk (acception sampling). Pengendalian kualitas proses dan produk juga dapat dibagi dua golongan menurut jenis datanya, yaitu data variabel dan data atribut. Variasi didefinisikan sebagai ketidakseragaman produk atau jasa yang dihasilkan. Variasi dikelompokkan menjadi 2 (dua) jenis [2]:

1. Variasi Terkendali (Controllable Variation)

Variasi terkendali adalah variasi yang dapat dikendalikan atau variasi yang dapat dihilangkan atau diminimalisir jika kita melakukan aktivitas-aktivitas perbaikan. 
Contoh jenis variasi ini adalah kurang homogennya bahan baku, kurang cermatnya operator, dll.

\section{Variasi Tidak Terkendali (Uncontrollable Variation)}

Variasi tidak terkendali adalah variasi yang tidak dapat dikendalikan. Variasi jenis ini biasanya bersifat tidak stabil, tidak konsisten, tidak terprediksi, dan umumnya terjadi karena faktor alam lingkungan. Contoh variasi jenis ini adalah kelembaban udara, suhu ruangan yang berubah-ubah, dll.

\section{Diagram Kendali Atribut}

Atribut didefinisikan sebagai persyaratan kualitas yang diberikan kepada suatu barang, yang hanya menunjukkan apakah barang/ produk tersebut diterima atau ditolak. Diagram atribut biasanya digunakan untuk menganalisis pengukuran yang bersifat diskrit. Contohnya kelingan yang rusak pada badan pesawat, gelembung-gelembung udara pada botol/gelas, gesekan pada lempengan plat, dan sebagainya. Diagram ini dibagi menjadi dua jenis, yaitu [2]:

\section{Diagram P}

Diagram $\quad \mathrm{P}$ digunakan untuk memperlihatkan persentase item yang tidak sesuai. Contoh menghitung jumlah kursi rusak dan dibagi dengan jumlah total kursi yang diperiksa. Diagram $\mathrm{P}$ dapat disusun dengan jumlah sample tetap atau bervariasi. Dalam pembuatan diagram $P$ hal-hal yang perlu diperhatikan antara lain:

- Garis Tengah

$\mathrm{p}=\frac{\text { jumlah produk defect }}{\text { jumlah produk observasi }}$

dimana;

$\mathrm{p}$ : proporsi rata-rata

- Garis batas untuk p

$\mathrm{UCL}=\mathrm{p}+3 \mathrm{Sp}$

$\mathrm{LCL}=\mathrm{p}-3 \mathrm{Sp}$
$S p=\sqrt{\frac{p(1-p)}{n}}$

Dimana;

$\mathrm{n}=$ ukuran sampel

Dalam model ini, UCL dan LCL akan tervisualisasikan berfluktuasi. Ini berbeda dengan sampel konstan yang akan tervisualisasikan sebagai garis lurus. Pembacaan tetap sama apabila di luar UCL dan LCL maka sample berada pada out of control.

\section{Diagram C}

Diagram C digunakan untuk menunjukkan jumlah ketidaksesuaian suatu unit seperti unit kursi, lembaran baju, mobil, dll. Diagram $\mathrm{C}$ bertujuan menghitung jumlah defect unit produk yang tetap. Contohnya menghitung jumlah kerusakan (goresan, potongan, dll) pada tiap kursi dari 100 sample kursi.

\section{Analisis Penyimpangan [6]}

a. Proses Terkendali

Terjadi variasi karena penyebab acak yang normal. Tidak diperlukan tindakan apaapa.

b. Proses Tak Terkendali

Terjadi variasi karena penyebab yang tidak normal. Diperlukan tindakan penyelidikan. Beberapa pola grafik memberikan gambaran tentang indikasi terjadinya penyimpangan tak terkendali dalam proses, antara lain:

- Terdapat titik di luar garis batas (atas UCL atau bawah LCL)

- Terdapat dua titik di dekat garis batas kendali

- Terdapat larinya (run) lima titik di atas atau di bawah garis tengah (CL)

- Kecenderungan (trend) lima titik terus naik atau turun

\section{METODE PENELITIAN}

Adapun metode penelitian yang dilakukan adalah mengikuti diagram alir penelitian seperti yang ditunjukkan pada Gambar 1. 


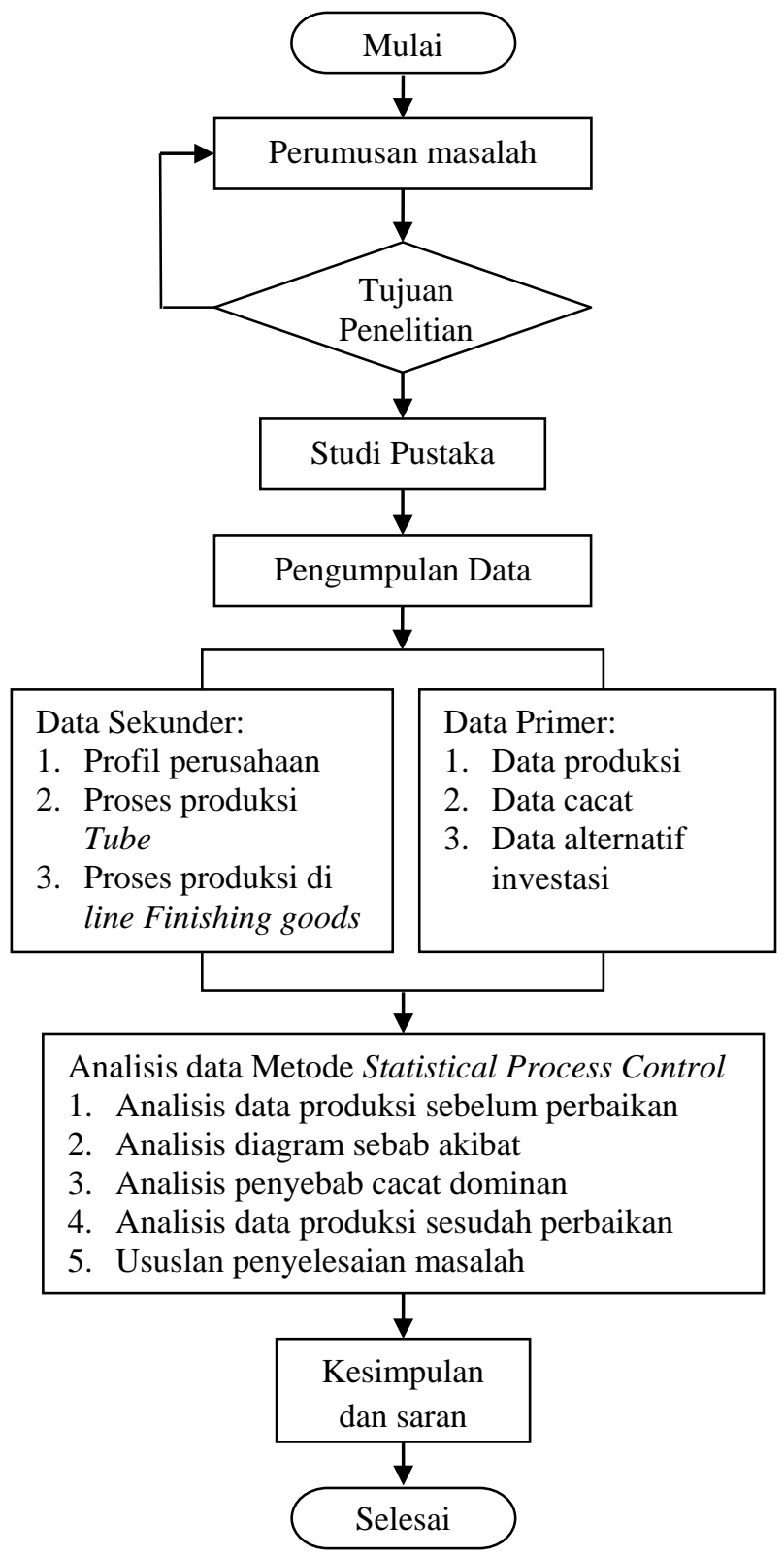

Gambar 1. Diagram Alir Penelitian

\section{HASIL DAN PEMBAHASAN}

Data produksi dan data cacat produk sebelum perbaikan pada line finishing untuk varian tube Pond's WB Pinkish FF 24 x 100gr bulan Januari sampai Oktober 2014 dapat dilihat pada Tabel 1.

Data pada Tabel 1 menunjukan bahwa untuk bulan Januari sampai dengan Oktober 2014 di line finishing process memiliki defect yang beragam dan penyumbang reject terbanyak adalah reject kotor dalam. Hal inilah yang untuk melakukan improvement secara otomasi pada line produksi ini, secara khusus di line finishing process untuk meningkatkan efisiensi dalam pelaksanaan proses produksi.

Tabel 1. Data Produksi Januari-Oktober 2014 Tube Pond's WB Pinkish FF 24x100g

\begin{tabular}{lrrc}
\hline \multicolumn{1}{c}{2014} & Jumlah & $\begin{array}{c}\text { Rata- } \\
\text { Rata }\end{array}$ & $\begin{array}{c}\text { Persentase } \\
(\%)\end{array}$ \\
\hline Gross & 7478271 & 830919 & \\
Netto & 6906104 & 767345 & \\
Reject & 572167 & 63574 & 7,65 \\
- kotor dalam & 320414 & 35602 & 56 \\
- Scratt & 183093 & 20344 & 32 \\
- warna cap & 22887 & 2543 & 4 \\
- cap pecah & 18309 & 2034 & 3 \\
- Header cacat & 16021 & 1780 & 3 \\
- cap terbalik & 6866 & 763 & 1 \\
- penyok & 4577 & 509 & 1 \\
\hline
\end{tabular}

\section{Pengendalian Proses Statistikal}

Proses yang dikendalikan secara statistical pada produk tube Pond's WB Pinkish FF 24x100g adalah pengendalian kualitas atribut. Pada pengendalian kualitas atribut ini terdapat tahapan yang dilakukan meliputi

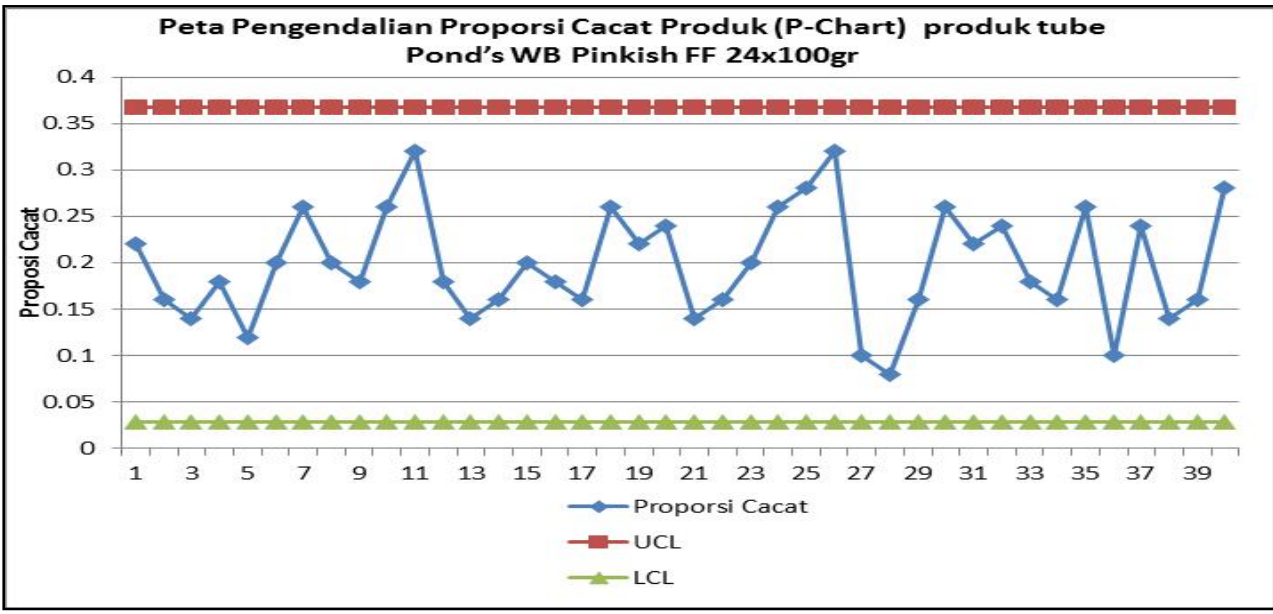

Gambar 2. Peta Pengendali Proporsi Cacat Tube Pond's WB Pinkish FF 24x100gr 
perhitungan peta kendali kualtas atribut, perhitungan proporsi cacat, perhitungan kapabilitas proses atribut. Peta kendali kualitas atribut yang digunakan untuk produk tube Pond's WB Pinkish FF 24x100g yang sesuai dengan standar inspeksi yang dilakukan yaitu dengan menggunakan peta kendali p.

Dari Gambar 2 dapat diketahui jika data telah berada dalam batas kendali yang berarti bahwa proses telah berjalan dengan stabil. Proporsi cacat berada diantara 0,028 sampai dengan 0,367. Hal ini dapat terjadi karena berbagai faktor seperti faktor manusia, metode kerja, lingkungan kerja, bahan baku dan material yang digunakan.

\section{Analisis Cause Effect Diagram}

Berdasarkan analisis penyebab reject tertinggi berada pada cacat foreign matter atau kotor dalam. Dengan itu aka dilakukan langkahlangkah perbaikan menggunakan aspek-aspek cause \& effect diagram (Fish Bone Diagram), sebagai berikut:

\section{Mesin}

- Permasalahannya mesin tidak dibersihkan secara berkala

a. Kondisi mesin dengan proses masih sangat manual dan tidak terawat yang jarang dibersihkan dari debu sekitar. Operator jarang membersihkan karena akan menimbulkan downtime pada laporan produksinya.

b. Selain itu udara yang dipakai belum terbebas secara baik dari oli, hal itu dikarenakan compressor belum dilengkapi filter oli. Hal ini juga berpotensi debu menempel dan melekat pada oli.

- Action yang dilakukan mengembangkan dan membuat mesin Blowing and Vacuum yang bekerja secara otomastis.

\section{Manusia}

- Permasalahannya operator tidak menjalankan SOP dengan baik dan benar.

a. Hal itu disebabkan karena operator terlalu sibuk sehingga sering menunda pekerjaan dan dikejar waktu produksi sehingga pada saat memegang produk tube tidak menggunakan sarung tangan.

b. Operator tidak mengontrol kelayakan part secara berkala karena pembagian tugas yang belum jelas dan part pengganti belum ada.

- Action yang dilakukan memberikan peraturan untuk handling produk harus memakai sarung tangan dan dibuatkan one point lesson.

\section{Material}

- Material Supply yaitu box (kardus) masih mengandung serpihan kardus bekas proses cutting dari supplyer.

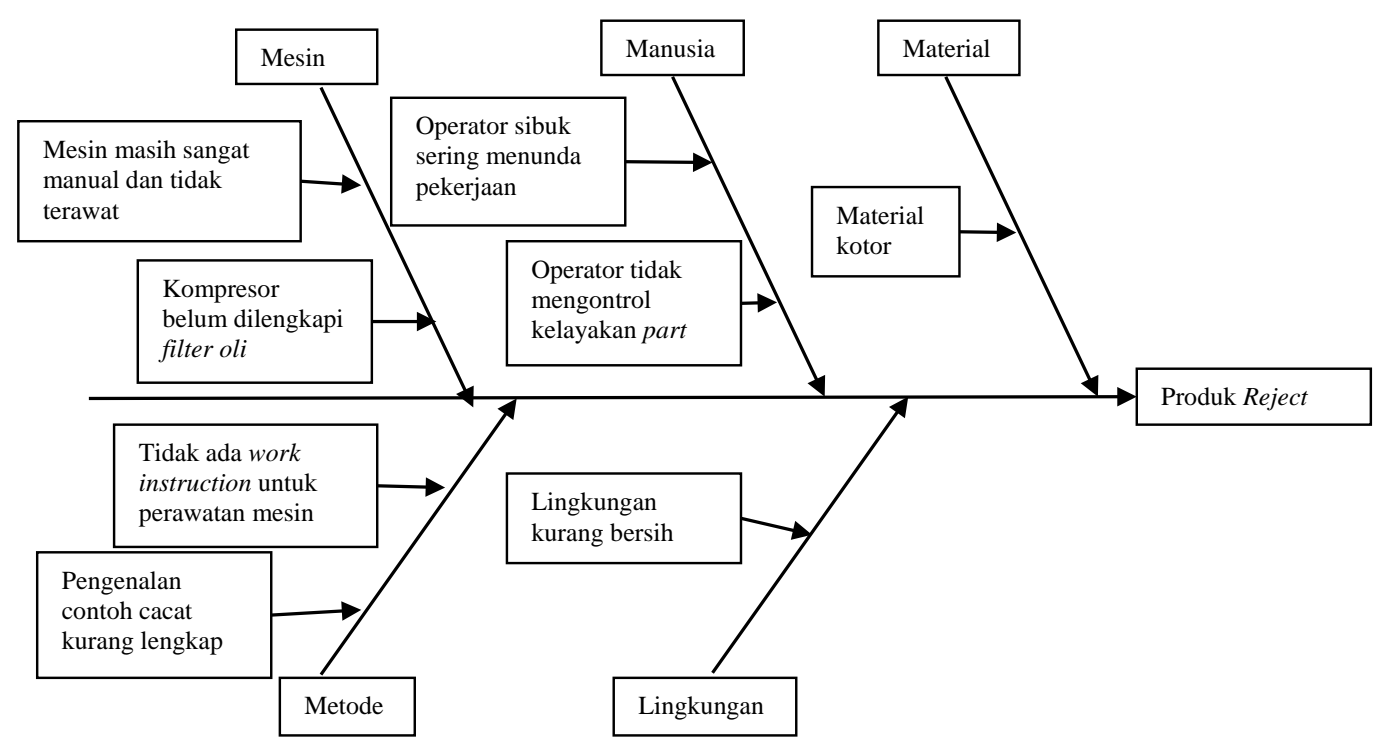

Gambar 3. Diagram Sebab Akibat 
a. Box embalage untuk tube set kotor

b. Sisa cutting yang tertinggal dalam celah box keluar saat terkena goncangan saat delivery

- Action yang dilakukan memasang lakban disepanjang permukaan box yang terkena proses cutting.

\section{Metode}

- Permasalahannya prosedur perawatan mesin kurang lengkap, waktu perawatan relative lama dan perlu menghentikan produksi selama perawatan.

a. Tidak ada Work Instruction untuk perawatan mesin.

b. Pengenalan contoh cacat kurang lengkap.

- Action yang dilakukan memberikan sosialisasi WI kepada operator dan dibuatkan WI untuk line finishing goods.

\section{Lingkungan}

- Permasalahannya ruangan kurang bersih karena belum dipartisi dengan area warehouse dan area mesin yang lain. Pendingin udara juga masih menggunakan pendingin yang biasa belum memakai udara yang berion positif.

Area capping bersebelahan dengan area WH yang hanya dibatasi oleh pagar besi.

- Action yang dilakukan pemasangan dinding pembatas antara area WH dan area capping dengan menggunakan sandwitch panel dan memasang air conditioner bermuatan ion positif yang sudah dimurnikan.

\section{Analisis Investasi}

Mesin Blowing and vacuum ini dioperasikan oleh satu operator setiap shiftnya dan dalam satu harinya membutuhkan tiga operator. Perbandingannya dengan manual

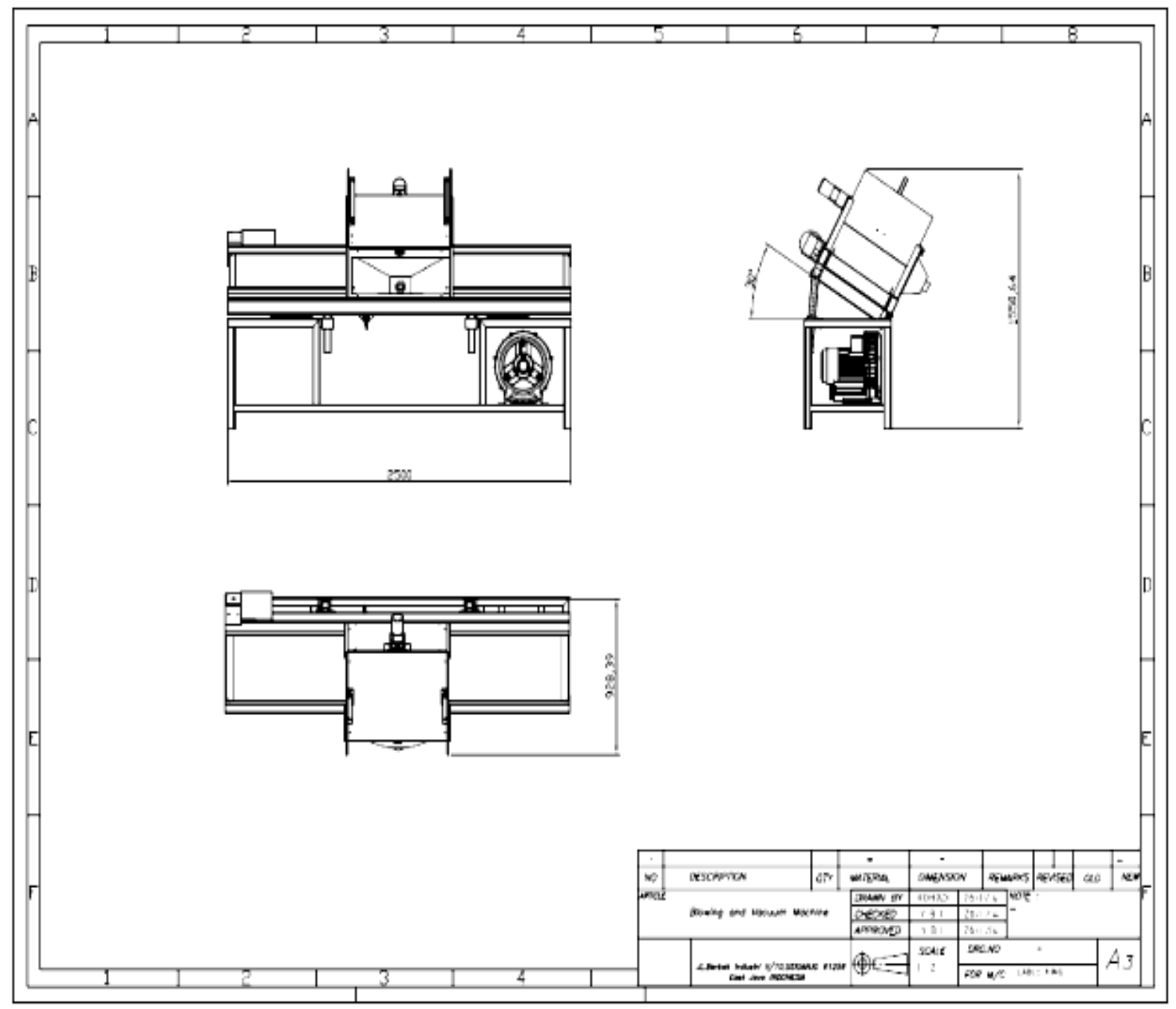

Gambar 4. Desain Mesin Blowing and Vacuum 
blowing and vacuum yang dilakukan dahulu, jika pekerjaan ini dilakukan secara manual membutuhkan operator sebanyak dua orang setiap shiftnya dan enam orang setiap harinya. Proyek ini sekaligus dipersiapkan untuk menghadapi kenaikan upah minimum pegawai yang setiap tahunnya mengalami kenaikan kurang lebih 20\%. Prinsip kerja dari mesin ini sangat sederhana yaitu actuator yang dipakai motor listrik dan piston udara yang dikendalikan oleh PLC. PLC memperoleh sinyal dari sensor. Inti utama dari mesin ini sebenarnya hanya conveyor yang dimodifikasi dengan menambahkan motor blowing dan vacuum. Piston untuk menyemburkan udara positif ini digerakan dengan linier motor agar dapat bergerak maju mundur dengan tujuan produk tube dapat mendapatkan tekanan udara positif. Dalam proses blowing dengan udara muatan positif ini di tempatkan di ruangan yang tertutup yang sebesar kardus produk finish goods, saat proses itu berlangsung motor vacuum mulai bekerja untuk menghisap partikel asing yang terkandung di produk maupun di kardus produk. Udara yang digunakan dalam proses ini mengandung muatan positif karena dipasangi anti statis di ujung air sprayer. Jadi bila perusahaan menginvestasikan mesin Blowing and Vacuum dengan harga, kecepatan dan biaya yang menunjang mesin tersebut akan balik modal pada 0,54 tahun dari pembelian mesin dan langsung beroperasi. Selain itu dapat mengurangi orang berjumlah 4 orang yang merupakan bentuk cost saving. Selain mesin ini ada investasi lain yaitu Clean Room with sandwitch panel dan Air Conditioner with purified air.

\section{Analisis Data Produksi Sesudah Perbaikan}

Sebagai bahan pertimbangan atas keseluruhan analisis yang telah dilakukan di bulan Januari sampai Februari 2015 dalam pelaksanaan metode otomasi yang dilakukan untuk mengubah proses blowing and vacuum secara manual diganti dengan mesin blowing and vacuum yang bekerja secara otomasi, maka perlu dilakukan kembali pembuktian untuk mengukur tingkat keberhasilan improvement otomasi tersebut. Dengan menggunakan alat yaitu dengan Statistical Process Control, dimana analisis berdasarkan kerugian dari reject yang dihasilkan selama proses produksi akibat dari pekerjaan yang dilakukan secara manual yang berpotensi menimbulkan cacat dari kualitas produk yang dikeluarkan.

Tabel 2 menunjukkan analisis data setelah perbaikan menggunakan otomasi dalam bentuk mesin conveyor yang dilengkapi penyemprot yang bekerja secara otomatis selama kurun waktu 2 bulan yaitu bulan Januari dan Februari 2015.

Tabel 2. Data Produksi Bulan Januari - Februari 2015 tube Pond's WB Pinkish FF $24 \times 100 g r$

\begin{tabular}{lrrc}
\hline \multicolumn{1}{c}{2015} & $\begin{array}{c}\text { Jumlah } \\
\text { (unit) }\end{array}$ & $\begin{array}{c}\text { Rata-Rata } \\
\text { (unit) }\end{array}$ & $\begin{array}{c}\text { Persentase } \\
\text { (\%) }\end{array}$ \\
\hline Gross & 3068812 & 1534406 & \\
Netto & 3033950 & 1516975 & \\
Reject & 34862 & 17431 & 1,140 \\
$\quad$ kotor dalam & 19523 & 9761 & 55,90 \\
Scratt & 11156 & 5578 & 32,3 \\
warna cap & 1394 & 697 & 3,80 \\
cap pecah & 1116 & 558 & 3,10 \\
Header cacat & 976 & 488 & 2,90 \\
cap terbalik & 418 & 209 & 1,10 \\
penyok & 279 & 139 & 0,90 \\
\hline
\end{tabular}

Gambar 2 Data pada grafik di atas menunjukkan bahwa untuk bulan Januari sampai dengan Februari 2015 di line finishing process mengalami penurunan di bulan-bulan ini dan di bulan-bulan tersebut didukung dengan sudah adanya mesin vacuum blowing yang bekerja secara otomasi. Pada bulan ini perusahaan sudah mengurangi man power atau operator yang berjumlah 1 orang setiap shiftnya atau 3 orang untuk 3 regu. Oleh sebab itu jumlah reject turun dan bernilai bagus karena tidak bergantung dengan man power sehingga pada saat istirahat mesin ini dapat tetap berjalan. Berdasarkan fakta ini, departemen produksi sudah melakukan cost saving yang dilatarbelakangi karena setiap tahunnya nilai upah minimum karyawan mengalami kenaikan kurang lebih sekitar 20\%. Pada saat observasi lapangan setelah dilakukan improvement ini, ditemukan fakta bahwa di line finishing ini mesin otomatis ini bekerja efektif. Mesin yang bekerja otomatis ini mempunyai cycle time hanya 10 detik. Hal inilah yang menyebabkan tingkat produktivitasnya meningkat. 
Tabel 2 merupakan data output actual dan output bersih yang lolos kualitasnya setelah dilakukan improvement. Dapat dilihat bahwa rate of quality-nya pada bulan tersebut mencapai target perusahaan dimana target yang ditetapkan perusahaan di bawah 2\%. Di bulan Januari ini ruang yang dimana dipakai mesin ini udaranya belum memakai udara yang bermuatan positif, sehingga debu masih dapat berpotensi menempel ke produk. Untuk bulan Februari ini mesin ini sudah berjalan lancar. Hasilnya dapat dilihat dari data di atas bahwa bulan ini dapat mencapai target reject. Hal ini dikarenakan mesin ini sudah dilengkapi anti statik pada sumber udara yang digunakan untuk menyemprot produk. Selain itu pada ruangan mesin ini dilengkapi dengan udara yang bermuatan positif sehingga debu hampir tidak ada di ruangan mesin ini.

Data defect reject pada Tabel 2 menunjukan bahwa kotor dalam, scratt, warna cap, cap pecah dan header cacat masih menjadi five big losse di bulan ini. Peringkat teratas untuk penyumbang reject terbanyak adalah kotor dalam dengan jumlah reject terbanyak yaitu 19.523 buah. Jumlah reject di bulan ini turun dalam presentase yaitu sebesar 6,52\% dari bulan sebelum improvement. Bulan-bulan ini jumlah reject mencapai 34.862 buah atau $15,35 \%$ dari output. Secara garis besar hasil reject setelah dilakukan improvement ini di bawah budget reject yang dibudgetkan $2 \%$ yang bernilai 1,14\%. Fakta ini menunjukan bahwa persentase reject berkurang. Faktor menurunnya reject ini disebabkan improvement yang dilakukan.

Dari hasil pengolahan data diatas bahwa setelah dilakukan pemasangan mesin blowing and vacuum terlihat jelas peningkatannya. Dilihat dari segi jumlah reject setiap proses produksi Data diatas bahwa setelah dilakukan pemasangan mesin blowing and vacuum terlihat jelas peingkatannya. Pada analisis bulan kedua ini team blowing and vacuum improvement yang menanggani projek ini mengambil sebuah keputusan. Keputusan yang diambil adalah pengurangan direct labor. Selain melakukan keputusan dari segi teknik, team juga mengambil keputusan di bulan ini juga diadakan pengurangan orang. Pengurangan orang ini akibat dengan adanya mesin blowing and vacuum yang cukup menggantikan 6 orang operator per harinya untuk 3 regu. Keputusan ini didasari dengan pengurangan direct labor dan beban kenaikan upah minimum pegawai secara sektoral di tahun 2015 ini yang mencapai Rp. 3.230.400,-. Dilihat dari tabel dibawah ini menunjukan bahwa monitoring ini mengalami peningkatan dengan hasil yang hampir sempurna, sehingga dapat disimpulkan bahwa improvement yang dilakukan meningkatkan produktivitas dari bulan Januari-Oktober 2014 bulan pengamatan, November-Desember Bulan Pengembangan Blowing and Vacuum Machine dan Januari sampai Februari 2015 bulan implementasi berbuah baik atau berhasil dan memberikan peningkatan produktivitas di line finishing.

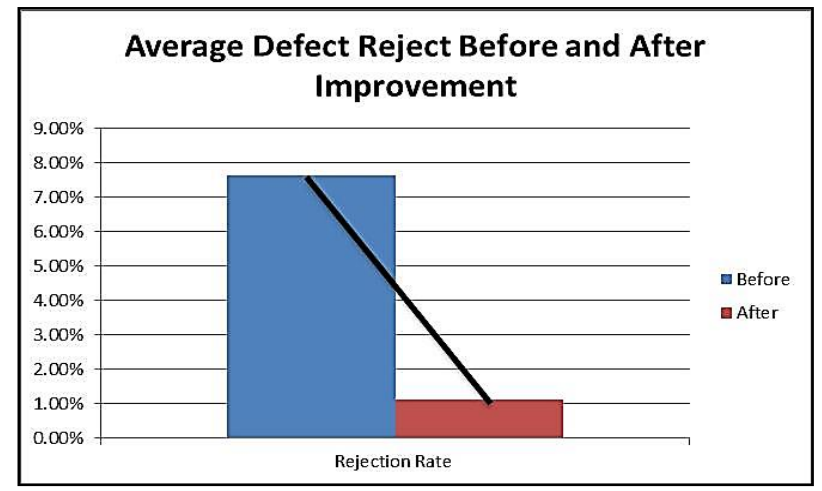

Gambar 5. Average Persentase Cacat Sebelum dan Sesudah Perbaikan Tube Pond's WB Pinkish FF 24x100g

Berdasarkan tabel dan grafik di atas dapat dilihat bahwa laporan line finishing process pada bulan Januari-Februari 2015 tingkat keberhasilan atau pencapaian tindakan improvement untuk manual blowing and vacuum digantikan dengan mesin blowing and vacuum yang bekerja secara otomasi menghasilkan reject dari defect kotor dalam dapat berkurang tetapi untuk reject scratt menjadi reject terbanyak. Hasil di kedua bulan ini mencapai target yang diharapkan yaitu persentase reject dibawah $2 \%$ yang menjadikan improvement yang dilakukan berhasil untuk meningkatkan produktivitas di line finishing process. Jumlah reject di bulan ini turun dalam presentase yaitu sebesar $6,52 \%$ dari bulan sebelum improvement. 
Tabel 3. Kesimpulan Perbaikan Kualitas

\begin{tabular}{lcc} 
& Januari-Oktober 2014 & Januari-Februari 2015 \\
\cline { 2 - 3 } & Sebelum Perbaikan & Setelah Perbaikan \\
\hline Rejection Rate & $7,65 \%$ & $1,14 \%$ \\
Defect Reject of Kotor Dalam & $4,38 \%$ & $0,64 \%$ \\
Capability & 1,1217 & 1,2867 \\
Man Power & 6 orang & 0 orang \\
Failure Cost & Rp. 120.842.300,00 & Rp. 35.477.750,00 \\
\hline
\end{tabular}

Berdasarkan hasil perbaikan di atas dapat diketahui bahwa kemampuan proses mengalami peningkatan untuk tube Pond's WB Pinkish FF $24 \times 100 g$ dari rata-rata per bulan sebelum perbaikan 63.574 pcs dan sesudah perbaikan menjadi 17.431 pcs. Perbaikan yang sudah diimplementasikan bukan hanya mengurangi biaya tenaga, biaya waktu dan cacat produk tetapi meningkatkan kemampuan proses dan menghasilkan analisis kegagalan untuk pengembangan proyek selanjutnya.

\section{KESIMPULAN}

Berdasarkan hasil dari pengolahan dan analisis data maka diperoleh bahwa tidakan yang perlu dilakukan untuk mengurangkan produk cacat adalah: mengembangkan dan membuat mesin Blowing and Vacuum yang bekerja secara otomastis, memberikan peraturan untuk handling produk harus memakai sarung tangan dan dibuatkan one point lesson, memasang lakban di sepanjang permukaan box yang terkena proses cutting, memberikan sosialisasi WI kepada operator dan dibuatkan WI untuk line finishing goods, memasangan dinding pembatas antara area $\mathrm{WH}$ dan area capping dengan menggunakan sandwitchpanel dan memasang air conditioner bermuatan ion positif yang sudah dimurnikan. Dari hasil implementasi diperoleh penurunan rata-rata produk yang reject dari 7,65\% menjadi 1,14\%, untuk defect reject dalam box yang kotor turun dari 4,38\% menjadi $0,64 \%$ dan pengurangan failure cost dari Rp 120.842 .300 menjadi Rp. 35.477.750.

\section{DAFTAR PUSTAKA}

[1]. Zagbel, T. Yuri M.Z. dan Rahmat Nurcahyo, 2013, TQM Manajemen Kualitas Total Dalam Perspektif Teknik Industri, PT. Indeks, Jakarta

[2]. Montgomery, D., C., 1985. Introduction to Statistical Quality Control. New York: John Wiley \& Sons

[3]. Gasperz, Vincent, 2003, Metode Analisis Untuk Peninngkatan Kualitas ISO 9001:2000 Clause 8: Measurement, Analysis and Improvement, Gramedia Pustaka Utama, Jakarta.

[4]. Heizer, Jay, and Render, Barry. 2009. Manajemen Operasi, edisi kesembilan. Salemba Empat, Jakarta.

[5]. Purnomo, Hari. 2004. Pengantar Teknik Industri, Graha Ilmu, Yogyakarta.

[6]. Sutanto, Eko. 2014. Analisis Kualitas Billet Dengan Metode Statistical Process Control (SPC) Pada PT. Hanil Jaya Steel. Universitas Negeri Surabaya: Jurnal Pendidikan Teknik Mesin, Fakultas Teknik, Universitas Negeri Surabaya. 